\title{
Oral Health Education Interventions among Anganwadi Workers in India: Meta Analysis and Review - A Short Communication
}

\author{
Authors \\ Dr Yogesh ${ }^{1}$, Dr Santosh Kaza ${ }^{2}$, Dr Mamta ${ }^{3}$, Dr Arun Singh ${ }^{4}$, Dr Thriveni BS \\ ${ }^{1}$ Public Health Foundation of India (PHFI), New Delhi. \\ ${ }^{2}$ UNICEF, Vishakhapatnam, India \\ ${ }^{3}$ Sudha Rastogi Dental College, Faridabad, India \\ ${ }^{4}$ Public Health Foundation of India (PHFI), New Delhi \\ ${ }^{5}$ Institute of Public Health (IPH), Bangalore \\ Corresponding Author \\ Dr Yogesh \\ H No. 206/B4, SRS Royal Hills, Sector 87, Faridabad - 121002, Haryana, India \\ Email: yogeshkind@gmail.com, Phone: +91-9896514876
}

\begin{abstract}
The services of Anganwadi workers $(A W W s)$ in India are commendable and significant in their working areas. Oral health also affects general health. The understanding and adaptation of oral health education has not progressed as it should be. AWWs can provide an efficient method of implementation of oral health education. Their capability and skills are dependable on their understanding and knowledge. Training is an effective technique to improve their understanding and knowledge towards oral health. This study analyzed the efficiency, viability and opportunity of oral health knowledge to a AWWs.
\end{abstract}

Keywords: $A W W s, O H E D, I C D S$, Oral Health, Anganwadi Workers

\section{Introduction}

In India, AWWs workers are one of the community workers of integrated child development services (ICDS), who provide services like supplementary nutrition, referral services, pre-school formal education, nutrition \& health education and assist ANM in immunization, health check-ups to community, adolescents and children up-to 6 years of age. Nutrition health and education (NHED) are the key domain and services in ICDS.AWWs get trainings and hands-on regularly on Behavior Change Communication (BCC) and capacity building strategies along with health and its key areas where the AWWs work. ${ }^{1}$ Trainings are kind of interventions which are believed to be one of the best for capacity development of AWWs.

Oral diseases are serious public health problem which affect the overall health of a person. ${ }^{2}$ The integration of oral health promotional strategy with general health has been advised. ${ }^{3}$ Oral health education (OHED) is a widely used effective in- 
tervention at schools settings that have resulted in induced changes in oral habits, knowledge, practice and routine. ${ }^{4}$ But, the Anganwadi centers or AWWs have not been involved in oral health education nationally and on generalized basis. Participation of AWWs in community oral health and formulation of comprehensive additional strategy in this area is highly needed. The idea of inclusion of oral health education in Anganwadi centers has been supported by many researchers. ${ }^{5}$

Repeated practical reorientation training has significant role in strengthening the knowledge and skills of Anganwadi workers. ${ }^{6}$ Where as, the impact of training and interventions is also crucial in formulating the policies and intervention programs. Some studies have been conducted to access the impact of oral health training programs to Anganwadi workers on their knowledge and skills about oral health. ${ }^{7,8,9,10}$ This review and metaanalysis was conducted to conclude the impact and feasibility of such oral health training programs on Anganwadi workers.

\section{Methods, Results and Discussion}

Online databases PubMed and Cochrane were searched for articles published in English languages. Keywords "Anganwadi workers" AND "Before-After study", "AWWs" OR "BeforeAfter study", "AWWs" AND "India" AND "Oral Health" AND "Pre-Post Study" were used in online search. Intervention studies/before-after studies were considered for this review and metaanalysis. Studies with OHED interventions on Anganwadi workers in Indian context were only selected. Statistical analysis was performed in MedCalc Version 15.8. Studies failed to present clear results and conclusions were excluded. A total of 4 (plus one) studies met our criteria and selected for this review and meta-analysis (Table 1). One study was case control and 3 studies were before-after/Intervention studies. One study by Goel S et al. had two independent groups where each group had different type of intervention, thus both groups were included as individual studies. ${ }^{8}$ There was variability of sample size among studies, thus random effect model was chosen in this meta-analysis. Minimum sample size among all studies was 25 and maximum was 538. Total number of samples were 1005.Each included study described either the number of participants or proportion of participants with positive effect of intervention. The maximum percentage of positive effect of intervention among studies was 61.2 (CI: 54.6 - 67.5) and minimum was 48 (CI: 27.7 to 68.6). The percentage of overall positive effect of intervention was 56.1 (95\% CI: 51.9 to 59.1).

Figure 1. Forest plot of meta-analysis of 5 studies showing proportions of participants had positive effect of intervention. (* indicates same study but with different group and interventions)

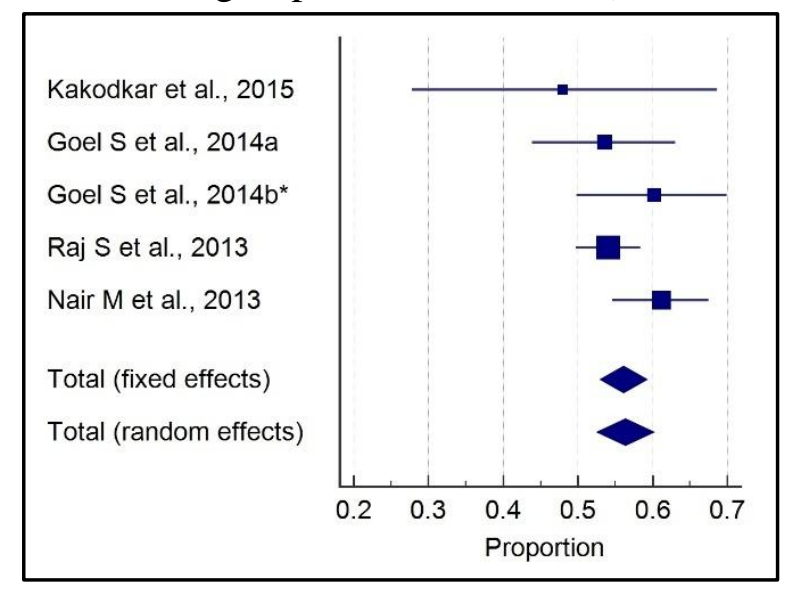

The statistics for heterogeneity $\left(\mathrm{I}^{2}\right)$ was19.5, which on quantitative measures has shown that the variability across studies was low. The chi-square statistics (Cochran's $Q=4.9$ ) was quite low as small number of studies were included in this review and meta-analysis. On the other hand, the heterogeneity was not found to be statistically significant $(\mathrm{p}=0.29)$.

The degree of freedom was almost equal to the chi-square statistics $\left(\mathrm{df} \approx \chi^{2}\right)$ i.e. no heterogeneity was observed in this meta-analysis. The overall effect (combined point estimate [according to random effect model]) of the studies included in this meta-analysis was 0.56 (CI: 0.52 to 0.59 , a conservative estimate [wider CI as compared to fixed effect model]), which has been shown as the diamond in forest plot (Figure 1).

Among the 5 studies in this meta-analysis and review, the positive effect of oral health education 
with 1005 Anganwadi workers was 56.1\% (95\% CI: 51.9 to 59.1). Variability between studies was ruled out. Study by Goel $S$ et al. included two independent groups with almost equal but somewhat different interventions. ${ }^{8}$ he effectiveness of both the interventions were statistically significant. Two groups received interventions which were same in many ways, except some modules.

Indirect interventions on parents and teachers have been adapted for oral health education. There are some studies which have been conducted on school teachers and primary health care workers and have shown significant effects of oral health interventions. $^{11,12,13,14,15}$

School oral health model can also be replicated. The school dental health intervention by Shenoy and Sequeira in Mangalore on 12 to 13 year old school children resulted in reduced plaque, gingivitis and highly significant changes were seen in knowledge and habits. ${ }^{12}$

Table 1. Meta-Analysis of Studies on Oral Health Interventions to Anganwadi Workers in India

\begin{tabular}{|c|c|c|c|}
\hline Study & Sample Size & Positive Effect (\%) & $95 \% \mathrm{CI}$ \\
\hline Kakodkar et al., $2015^{7}$ & 25 & 48.000 & 27.797 to 68.694 \\
\hline Goel S et al., $2014 \mathrm{a}^{8}$ & 112 & 53.571 & 43.902 to 63.047 \\
\hline 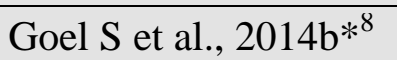 & 98 & 60.204 & 49.817 to 69.957 \\
\hline Raj S et al., $2013^{y}$ & 538 & 54.089 & 49.773 to 58.361 \\
\hline Nair M et al., $2013^{10}$ & 232 & 61.207 & 54.610 to 67.513 \\
\hline Total (fixed effects) & 1005 & 56.105 & 52.981 to 59.194 \\
\hline Total (random effects) & 1005 & 56.367 & 52.619 to 60.079 \\
\hline
\end{tabular}

Table 2. Test Statistics for Heterogeneity. (Significance Level at0.05)

\begin{tabular}{|l|c|}
\hline $\mathrm{Q}$ & 4.9714 \\
\hline $\mathrm{DF}$ & 4 \\
\hline Significance level & $\mathrm{P}=0.2902$ \\
\hline $\mathrm{I}^{2}$ (inconsistency) & $19.54 \%$ \\
\hline 95\% CI for $\mathrm{I}^{2}$ & 0.00 to 84.25 \\
\hline
\end{tabular}

\section{Conclusion}

In this review, studies with an oral health education interventions were considered. Few studies met our inclusion criteria and included in review and meta-analysis. No significant variation and heterogeneity in the results of included studies was observed. The results of this meta-analysis and review showed that oral health interventions can play an important role in improving the overall knowledge and skills of Anganwadi workers. There were lack of available evidences, as only few number of studies were available which have demonstrated oral health education intervention on Anganwadi worker.
This was one of the limitation in this review. From this study, it can be concluded that the oral health education (OHED) interventions can work in an effective way and can improve the knowledge and skills of Anganwadi workers. It is also recommended that integration and adaptation of oral health education in Anganwadi workers' training modules can improve the overall expertise and understanding about oral health. This may help in improving the status of oral health in community.

National wide effort for oral health education at primary level should be made, along with trainings to primary health care workers. Such kind of 
research would also help in formulating the policies and training for Anganwadi workers in general, which is one of the scope of this study. This study would also guide researchers in understanding and efficiency of OHED.

The authors declare no conflict of interest.

No financial support/grant received for this study.

\section{References}

1. Ministry of Women \& Child Development India. Anganwadi Workers and Integrated Child Development Services [Internet]. INTEGRATED CHILD DEVELOPMENT SERVICES (ICDS) SCHEME. 2009 [cited 2015 Oct 21]. Available from: http://wcd.nic.in/icds/icdsteam.aspx

2. Petersen PE. The World Oral Health Report 2003: continuous improvement of oral health in the 21 st century - the approach of the WHO Global Oral Health Programme. Community Dent Oral Epidemiol. 2003 Dec;31(s1):3-24.

3. Petersen PE. World Health Organization global policy for improvement of oral health--World Health Assembly 2007. Int Dent J. 2008 Jun;58(3):115-21.

4. Garbin C, Garbin A, dos Santos K, Lima D. Oral health education in schools: promoting health agents. Int J Dent Hyg. 2009 Aug;7(3):212-6.

5. Khatib N, Zodpey S, Zahiruddin Q, Gaidhane A, Patil M. Prevalence and determinant of early childhood caries among the children attending the Anganwadis of Wardha district, India. Indian J Dent Res. Medknow Publications and Media Pvt. Ltd.; 2013 Jan 1;24(2):199.

6. Davey A, Davey S, Datta U. Role of reorientation training in enhancement of the knowledge regarding growth monitoring activities by anganwadi workers in urban slums of delhi. Indian $\mathbf{J}$ Community Med. Medknow Publications; 2008 Jan 1;33(1):47-9.
7. Kakodkar P, Matsyapal C, Ratnani N, Agrawal R. Anganwadi workers as Oral Health Guides: An interventional study. J Dent Res Sci Dev. 2015;2(2):33.

8. Goel S, Goel N, Raj S, Sharma V, Ajay S. Evaluation of short term impact of two training packages on oral health knowledge and skills of Anganwadi workers of a Northern City of India: Before and after comparison study. SRM J Res Dent Sci. Medknow Publications and Media Pvt. Ltd.; 2014 Oct 1;5(4):237.

9. Raj S, Goel S, Sharma V, Goel N. Shortterm impact of oral hygiene training package to Anganwadi workers on improving oral hygiene of preschool children in North Indian City. BMC Oral Health. 2013;13(1):67.

10. Nair MKC, Renjit M, Siju KE, Leena ML, George B, Kumar GS. Effectiveness of a community oral health awareness program. Indian Pediatr. 2009;46 Suppl:s86-90.

11. Sandhya M, Shanthi M, Sudhir K, Fareed N, Kumar RVSk. Effectiveness of oral health education among primary health care workers at the primary health center in Nellore district, Andhra Pradesh. J Indian Assoc Public Heal Dent. Medknow Publications and Media Pvt. Ltd.; 2014 Apr 1;12(2):74.

12. Shenoy RP, Sequeira PS. Effectiveness of a school dental education program in improving oral health knowledge and oral hygiene practices and status of 12- to 13year-old school children. Indian J Dent Res. Medknow Publications and Media Pvt. Ltd.; 2010 Jan 1;21(2):253-9.

13. Petersen PE, Hunsrisakhun J, Thearmontree A, Pithpornchaiyakul S, Hintao J, Jürgensen N, et al. School-based intervention for improving the oral health of children in southern Thailand. Community Dent Health. 2015 Mar;32(1):44-50. 
14. Kay EJ, Locker D. Is dental health education effective? A systematic review of current evidence. Community Dent Oral Epidemiol. 1996 Aug;24(4):231-5.

15. Gao X, Lo ECM, McGrath C, Ho SMY. Innovative interventions to promote positive dental health behaviors and prevent dental caries in preschool children: study protocol for a randomized controlled trial. Trials. 2013 Jan;14(1):118. 